\title{
Escrever o luto
}

Writing the Mourning

\author{
Eurídice Figueiredo' (iD) 0000-0002-8265-3034
}

'Universidade Federal Fluminense, Programa de Pós-Graduação em Estudos de Literatura, Niterói, RJ, Brasil. 24210-201 - secretaria.literatura@gmail.com

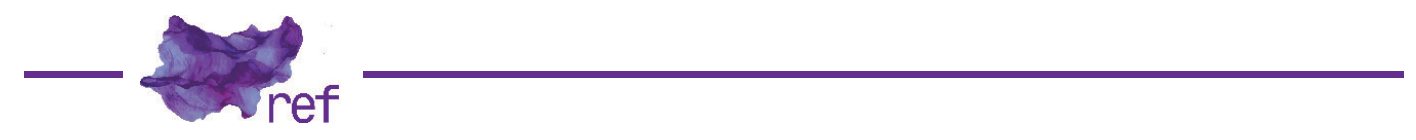

ROCHA, Rosângela Vieira.

O coração pensa constantemente.

Cajazeiras (PB): Arribaçã, 2020.

\begin{abstract}
O mundo em que vivemos oferece-nos a cada dia a espetacularização da morte. Há mortes que têm impacto histórico imediato, como o assassinato do arquiduque Francisco Ferdinando em Sarajevo em 1914, que deu início à Primeira Guerra, o suicídio de Getúlio Vargas em 1954, a morte de Tancredo Neves que levou José Sarney à presidência. O atentado terrorista ao World Trade Center de Nova York em 11 de setembro de 2001 teve decorrências geopolíticas importantes, como a guerra do Iraque, além de ter causado impacto visual, pois todas as pessoas assistiram à catástrofe na televisão. Desde o fim de 2019 o mundo foi tomado pela pandemia da covid-19 que já provocou a morte de mais de quatro milhões de pessoas; enfim, a vida e a morte estão ligadas e, apesar de nós, Ocidentais, querermos fugir da morte, ela está invadindo nossas casas em todos os tipos de tela. Nesse momento de reclusão, somos levados a pensar no luto que afeta tantas famílias. Diferente da morte espetacularizada de políticos importantes ou estrelas do mundo do entretenimento, diferente dos grandes ataques terroristas que mobilizam multidões, há a morte privada, que não rende notícia no jornal, e que só atinge os próximos. $\mathrm{E}$, às vezes, toca tão profundamente que os parentes têm dificuldade de continuar vivendo sem a presença daquela pessoa, tão simples, mas tão fundamental.

Rosângela Vieira Rocha escreveu dois romances autobiográficos, O indizível sentido do amor (2017) e O coração pensa constantemente (2020), para elaborar o luto, respectivamente, pela perda do marido e, anos depois, da irmã mais velha. O marido é chamado de José e a irmã recebe o nome fictício de Rubi, porque era uma verdadeira pedra preciosa. Em cada um dos romances, ao se colocar diante da morte, a autora rememora os últimos momentos, a doença, a vida pregressa daquelas pessoas que foram tão íntimas durante anos e agora jazem mortas.

Embora soubesse vagamente da militância do marido durante a ditadura, a narradora tem pouca informação porque ele não gostava de falar sobre o passado. Assim, já no primeiro capítulo de $O$ indizível sentido do amor ela conta que viajou a Portugal para encontrar Alípio Cristiano de Freitas, que tinha tido contato com o marido na prisão da llha Grande; ambos foram torturados, resistiram, não delataram os companheiros. A narradora precisa dessas informações para completar o seu livro, para "fechar uma ferida, diminuir esse peso que [lhe] dobra os joelhos" (Rosângela ROCHA, 2017, p. 13). A viagem acaba sendo muito agradável, pela calorosa acolhida de Alípio e sua esposa, pela possibilidade de visitar o país e espairecer.
\end{abstract}


Apesar das sequelas que afetaram sua saúde a vida inteira, apesar das perseguições sofridas em seus empregos, o marido se calava porque a pessoa traumatizada evita voltar para trás e reviver os momentos dolorosos; não é discrição, não é timidez, é difícil enfrentar os fantasmas da tortura. O trauma tem essa dimensão aporética já que é impossível lembrar e é igualmente impossível esquecer. Lembrar causa sofrimento, ao mesmo tempo, a pessoa não consegue esquecer.

No caso da irmã, a rememoração volta à infância: sendo a narradora a caçula, ela admirava a mais velha por sua beleza, sua presença, seu carinho quase-materno. Ao evocar esse passado mais longínquo numa cidadezinha do interior de Minas, retrata a vida acanhada de uma família da pequena burguesia nos anos 1950-60. Reconstrói cenas como o footing das moças para flertar com os rapazes, os dramas nas escolhas das roupas com poucos recursos, os comportamentos erráticos e moralistas dos pais.

O romance começa com uma cena significativa. A narradora precisa comer, mas não consegue engolir nada uma semana após a morte da irmã. Tira a tampa da vasilha da bacalhoada, prato predileto da irmã. "Mas em poucos segundos começa a náusea, a lava, a tontura, o nojo, e tenho de correr para não vomitar ali mesmo, na fila da comida" (Rosângela ROCHA, 2020, p. 13). Não é por acaso que luto e nojo são sinônimos, a pessoa enlutada não tem apetite, sente engulhos só de pensar em pratos que, em outras ocasiões, pareceriam saborosos e tentadores.

Escrever é tentar exorcizar a morte, o impasse em que se encontra diante do vazio criado pela ausência da pessoa amada. Roland Barthes, no dia seguinte ao da morte de sua mãe, em 26 de outubro de 1977, começou um Diário de luto, obra inspiradora para Rosângela Rocha, que aparece em uma das epígrafes de $O$ indizível sentido do amor. Barthes diz que escreve não para se "lembrar, mas para combater a dilaceração do esquecimento na medida em que ele se anuncia absoluto" (Roland BARTHES, 2011 , p. 110, grifos do autor). Durante os seis meses que durou a doença da mãe, ele estava "perdidamente por conta dela" (BARTHES, 2011, p. 16). Para elaborar seu luto ele escreve; porém, o ato mesmo de escrever choca-o porque isso revela que seu espírito está alerta. "O espantoso dessas notas é um sujeito devastado submetido à presença de espírito" (BARTHES, 2011, p. 30).

O sobrevivente se depara com a culpa por continuar vivo. "A razão da grande culpa, que me atormentou durante meses e que às vezes ainda aparece, sorrateira, me espezinhando, é o fato de eu estar viva" (ROCHA, 2017, p. 161). Barthes também afirma que a morte da mãe não Ihe tira o desejo de viver: "que essa morte não me destrua completamente, isso significa que decididamente desejo viver perdidamente, até a loucura, e que, portanto, o medo de minha própria morte continua aqui, não foi deslocado nem uma polegada (BARTHES, 2011, p. 21).

Há momentos em que o luto provoca desalento, o sobrevivente se pergunta por que não ele, por que foi o outro que morreu. Barthes se refere à acídia, falta de vontade de agir. No livro Monodrama, Carlito Azevedo (2009, p. 139) também escreveu sobre a morte de sua mãe a fim de manter o autocontrole: "Venho escrever por medo de perder a razão, não pelo estardalhaço dos nervos, que não há, mas pelo seu contrário sinuoso, a idiotia". Acídia e idiotia são sentimentos parecidos que apontam para um sofrimento interiorizado, nada espetacular, nada teatral.

Como Barthes se recusa a histerizar ou teatralizar o luto, a manifestar publicamente o seu sofrimento, o luto fica todo contido, fechado. No Diário de luto Barthes confronta seu desejo de luto privado e a pressão dos amigos para que se cure: o luto não é uma doença, não há cura possível. Não sendo contínuo, o sentimento do luto pode se voltar para a interioridade e para o silêncio ou, ao contrário, para as trivialidades externas: trata-se, no primeiro caso, de uma atitude mais nobre e solitária, enquanto o segundo só desencadeia mais vazio ainda. Ao contrário do que se diz, o tempo não faz passar o luto, ele só elimina "a emotividade do luto" (BARTHES, 2011 , p. 98, grifo do autor). A morte das pessoas, públicas ou privadas, passa por vários momentos: "um acontecimento, uma ad-ventura, e como tal mobiliza, interessa, tensiona, ativa, tetaniza" (BARTHES, 2011 , p. 48). Todavia, esse momento mais visível e pungente passa, deixa de ser um acontecimento, "é uma outra duração, comprimida, insignificante, inenarrada, abatida, sem apelo: verdadeiro luto insuscetível de qualquer dialética narrativa" (BARTHES, 2011 , p. 48).

O luto se perpetua, porém de maneiras diferentes. Diferente de Barthes, Rosângela Vieira Rocha teatraliza o luto ao conseguir criar ficções, encenar os acontecimentos vividos. Nas intervenções em sua página do Facebook evoca datas de aniversário, fragmentos de lembranças tanto da irmã quanto do marido. E nos dois romances, percebe-se uma evolução nos sentimentos da narradora: ora evoca a doença, ora se ocupa com a vida que continua pulsando; interroga-se sobre tudo o que poderia ou deveria ter feito, como se fosse possível saber quais eram as escolhas certas e racionais, quando ela mesma se dá conta de que a vida caminha aos trambolhões, não anda em linha reta. Fica sabendo, pelo sobrinho, que a irmã não gostava de suas conversas durante as últimas visitas que the fez no hospital; apesar de ser penoso, ela esforçava-se para ir vê-la, pensava fazer o melhor para distraí-la e, no entanto, suas boas intenções foram baldadas. 
A narradora divide o protagonismo com seus biografados porque, ao falar do outro, fala também de si, porque o eu só existe em relação com o outro e vice-versa. Ao final de O indizível sentido do amor ela se pergunta se o retrato que fez de seu marido era justo, depois se corrige para revelar que o que fez não foi, propriamente, a biografia do marido, mas da relação dos dois. "Mas não é a sua história, é a nossa, ou é a que imagino ser a nossa, ou o que gostaria que fosse, talvez seja a minha própria história" (ROCHA, 2017, p. 187). Em O coração pensa constantemente a narradora procede da mesma maneira, refere-se a uma relação de irmãs, dos afetos, das disputas, do ciúme e até das picuinhas tão comuns entre irmãs; fala também dos pais, de hábitos interioranos da época em que a irmã era mocinha e ela era uma criança curiosa e "abelhuda".

Barthes conta que nos últimos seis meses de vida da mãe, houve uma inversão de papéis: ela se tornou sua filha, porque necessitava de seus cuidados; de maneira similar, no livro Da vida nas ruas ao teto dos livros de Clarice Fortunato (2020), a narradora diz que os papéis foram se invertendo, ela se tornava mãe de sua mãe, cada vez mais enferma e cega, configurando uma confusão de estatutos. Após a morte da mãe, quando ela tinha 13 anos, a protagonista-narradora se sente muito só, órfã, e sem arrimo. Mesmo ao escrever o livro, a ferida está lá, não cicatriza nunca. "O amor, esse sentimento milagroso que nos conecta, é a fortaleza que me revigora das angústias e ameniza o vazio da sua existência na minha vida. E é pela transcendência desse mesmo amor que escrevo em sua memória" (Clarice FORTUNATO, 2020, p. 82).

A narradora de Rosângela Vieira Rocha coloca-se no presente da pandemia, o luto que sente pela perda da irmã se estende, adquirindo uma dimensão coletiva. "O luto por você, e por todos os outros que morreram e ainda vão morrer dessa doença [...]. A dor dos doentes e dos agonizantes mescla-se à minha, e todas se somam num único sentimento" (ROCHA, 2020, p. 153).

Nenhum luto é igual a outro, cada um tem uma tonalidade nos diferentes momentos vividos. Como escreve Marília Kubota (2020, p. 98): "O que se pode dizer quando se perde uma pessoa de seu convívio diário? [...] Vamos aprendendo a perder um pouco a cada dia para que no fim nada sobre. E assim seja mais leve a última perda, a do incomensurável ego". Não é que o luto passe, é uma ferida sempre aberta, às vezes mais dolorosa, às vezes mais apagada, mas ela está lá. O luto é nosso pão cotidiano.

\section{Referências}

AZEVEDO, Carlito. Monodrama. Rio de Janeiro: 7letras, 2009.

BARTHES, Roland. Diário de luto. Tradução de Leyla Perrone-Moisés. São Paulo: Martins Fontes, 2011.

FORTUNATO, Clarice. Da vida nas ruas ao teto dos livros. Rio de Janeiro: Pallas, 2020.

KUBOTA, Marília. Eu também sou brasileira. São Paulo: Lavra Editora, 2020.

ROCHA, Rosângela Vieira. O indizível sentido do amor. São Paulo: Patuá, 2017.

ROCHA, Rosângela Vieira. O coração pensa constantemente. Cajazeiras (PB): Arribaçã, 2020.

Eurídice Figueiredo (euridicefig@gmail.com) possui Doutorado em Letras Neolatinas pela Universidade Federal do Rio de Janeiro (1988) e Pós-doutorado Sênior pela UFMG (2009). Atualmente é professora associada aposentada da Universidade Federal Fluminense atuando no Programa de Pós-Graduação em Estudos de Literatura. Tem experiência na área de Letras, com ênfase em Literaturas de língua francesa, Literatura brasileira e Literatura Comparada, atuando principalmente nos seguintes temas: a ditadura brasileira, crítica feminista, representações da alteridade, as escritas de si na literatura contemporânea.

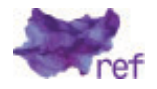


COMO CITAR ESTE ARTIGO DE ACORDO COM AS NORMAS DA REVISTA

FIGUEIREDO, Eurídice. "Escrever o luto". Revista Estudos Feministas, Florianópolis, v. 29, n. 3, e79375, 2021.

\section{CONTRIBUIÇĀO DE AUTORIA}

Conselho Nacional de Desenvolvimento Científico e Tecnológico - CNPq.

\section{FINANCIAMENTO}

Não se aplica.

\section{CONSENTIMENTO DE USO DE IMAGEM}

Não se aplica.

\section{APROVAÇĀO DE COMITÊ DE ÉTICA EM PESQUISA}

Não se aplica.

\section{CONFLITO DE INTERESSES}

Não se aplica.

\section{LICENÇA DE USO}

Este artigo está licenciado sob a Licença Creative Commons CC-BY 4.0 International. Com essa licença você pode compartilhar, adaptar, criar para qualquer fim, desde que atribua a autoria da obra.

\section{HISTÓRICO}

Recebida em 04/02/2021

Aceita em 24/05/2021 